BRAVILLIAN JOURNAL

www.bjournal.com.br
ISSN 0100-879X

Volume 43 (3) 182-267 March 2011

BIOMEDICAL SCIENCES

AND

CLINICAL INVESTIGATION

Braz J Med Biol Res, March 2011, Volume 44(3) 245-252

doi: 10.1590/S0100-879X2011007500003

Randomized clinical trial comparing the efficacy of the vaginal use of metronidazole with a Brazilian pepper tree (Schinus) extract for the treatment of bacterial vaginosis

S.R.R.F. Leite, M.M.R. Amorim, P.F.B. Sereno, T.N.F. Leite, J.A.C. Ferreira and R.A.A. Ximenes

The Brazilian Journal of Medical and Biological Research is partially financed by

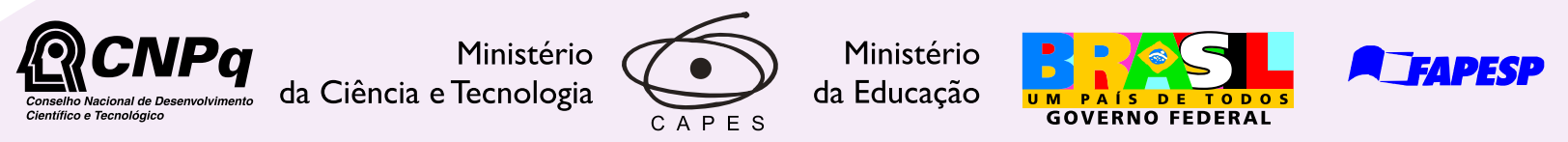

Institutional Sponsors
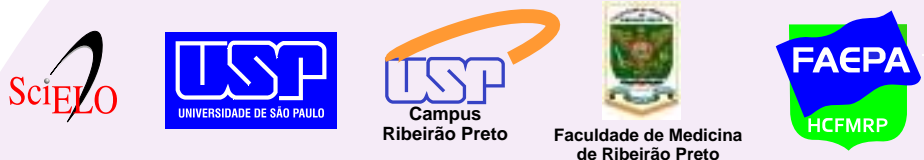

de Ribeirão Predic
Ministério

C A P E S $\oplus$ SHIMADZU Hotsite of proteomics metabolomics developped by:

GE Healthcare

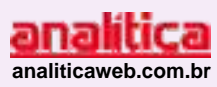




\title{
Randomized clinical trial comparing the efficacy of the vaginal use of metronidazole with a Brazilian pepper tree (Schinus) extract for the treatment of bacterial vaginosis
}

\author{
S.R.R.F. Leite ${ }^{1}$, M.M.R. Amorim²,3, P.F.B. Sereno4 ${ }^{4}$, T.N.F. Leite ${ }^{4}$, \\ J.A.C. Ferreira ${ }^{5}$ and R.A.A. Ximenes ${ }^{1}$ \\ ${ }_{1}^{1}$ Departamento de Pós-graduação em Medicina Tropical, \\ Universidade Federal de Pernambuco, Recife, PE, Brasil \\ 2Pós-graduação em Saúde Materno-Infantil, \\ Instituto de Medicina Integral Prof. Fernando Figueira, Recife, PE, Brasil \\ ${ }^{3}$ Instituto de Pesquisa Professor Joaquim Amorim Neto, Campina Grande, PB, Brasil \\ ${ }^{4}$ Instituto de Medicina Integral Prof. Fernando Figueira, Recife, PE, Brasil \\ ${ }^{5}$ Programa Institucional de Bolsas de Iniciação Científica (PIBIC/CNPq), \\ Faculdade Pernambucana de Saúde, Recife, PE, Brasil
}

\begin{abstract}
A $7.4 \%$ vaginal extract of the Brazilian pepper tree (Schinus terebinthifolius Raddi) was compared with $0.75 \%$ vaginal metronidazole, both manufactured by the Hebron Laboratory, for the treatment of bacterial vaginosis, used at bedtime for 7 nights. The condition was diagnosed using the combined criteria of Amsel and Nugent in two groups of 140 and 137 women, aged between 18 and 40 years. Intention-to-treat analysis was performed. Women were excluded from the study if they presented delayed menstruation, were pregnant, were using or had used any topical or systemic medication, presented any other vaginal infections, presented hymen integrity, or if they reported any history suggestive of acute pelvic inflammatory disease. According to Amsel's criteria separately, 29 patients (21.2\%) treated with the extract and $87(62.1 \%)$ treated with metronidazole were considered to be cured $(P<0.001)$. According to Nugent's score separately, 19 women $(13.9 \%)$ treated with the extract and $79(56.4 \%)$ treated with metronidazole were considered to be cured $(P<0.001)$. Using the two criteria together, the so-called total cure was observed in 17 women $(12.4 \%)$ treated with the extract and in 79 women $(56.4 \%)$ treated with metronidazole $(P$ $<0.001)$. In conclusion, the cure rate for bacterial vaginosis using a vaginal gel from a pepper tree extract was lower than the rate obtained with metronidazole gel, while side effects were infrequent and non-severe in both groups.
\end{abstract}

Key words: Bacterial vaginosis; Gardnerella vaginalis; Brazilian pepper tree; Metronidazole vaginal gel

\section{Introduction}

Bacterial vaginosis is a disorder of the vaginal ecosystem of polymicrobial etiology in which there is a predominance of anaerobic microorganisms and a marked reduction in the quantity of Lactobacillus or Döderlein's bacillus (1). It is the most frequent cause of vaginal discharge, observed in 22 to $50 \%$ of cases, and half of these women are asymptomatic (2-4). It is associated with obstetric and gynecological complications such as pelvic inflammatory disease, endometritis, urinary infection, and acquired immunodeficiency syndrome (5).

Studies have shown that one of the greatest risk factors for bacterial vaginosis is the use of intrauterine devices $(1,6)$. Other predisposing factors include new or multiple sex partners, use of vaginal douches, oral sex, and sex during menstruation $(1,2)$. The use of barrier methods and oral contraceptives seems to protect against bacterial vaginosis (4).

To treat bacterial vaginosis outside of pregnancy, metronidazole in a regimen of $500 \mathrm{mg}$ twice a day orally for 7 days or $0.75 \%$ metronidazole gel intravaginally in a single daily application for 5 days is recommended (6). Oral and vaginal metronidazole regimens have similar effectiveness,

Correspondence: S.R.R.F. Leite, Rua Félix de Brito e Melo, 854, Apto. 1302, 51020-260 Recife, PE, Brasil.

E-mail: soniarfigueiredo@uol.com.br

Received February 23, 2010. Accepted December 17, 2010. Available online January 14, 2011. Published March 7, 2011. 
ranging from 80 to $90 \%$ in different studies (3).

The great problem with antibiotic or chemotherapy medications is that, although effective for eradicating anaerobic agents, with high rates of clinical and microbiological cure, they do not improve the vaginal microbiota or may even modify it significantly (7). The standard treatments present a variety of unwanted effects, such as development of bacterial resistance and high rates of recurrence beyond the first month after treatment (8). These effects seem to occur through the action of medications on Lactobacillus, thereby modifying the vaginal ecosystem and causing failure or delay in restoration of the normal microbiota (9).

Schinus terebinthifolius Raddi is a small tree popularly known as the Brazilian pepper tree that is found along the Brazilian coast. Extracts from this tree have astringent, healing, anti-inflammatory, and antiallergic properties (10). Used gynecologically, such extracts produce apparent improvement in the vaginal microbiota, with reductions in the proportion of pathogenic microorganisms and increased quantities of Döderlein's bacilli (11). In 1999, a vaginal gel containing an extract from the Brazilian pepper tree (S. terebinthifolius Raddi) was launched on the Brazilian pharmaceutical market under the commercial name Kronel ${ }^{\circledR}$ (Hebron Laboratory, Brazil).

In 2003, a randomized clinical trial demonstrated a cure rate of $84 \%$ among patients with symptomatic vaginosis who were treated with topical vaginal application of a pepper tree extract, versus a cure rate of $47.8 \%$ with the use of a placebo (7). The 2003 trial presented several methodological limitations, such as the small number of women participating (48 patients), lack of investigation of the vaginal microbiota by means of culturing vaginal secretions before or after treatment, and basing the diagnosis solely on Amsel's criteria. This demonstrates the need to carry out new clinical trials to compare the use of conventional medications with the pepper tree extract, in terms of both effectiveness and safety, with evaluations of side effects and the impact on the vaginal ecosystem.

Thus, the present study aimed to fill some of these gaps in existing knowledge by comparing the effectiveness of two treatments for bacterial vaginosis, i.e., a pepper tree extract and metronidazole applied vaginally.

\section{Material and Methods}

A randomized double-blind clinical trial was conducted to compare a pepper tree extract and metronidazole for treating bacterial vaginosis among women attended at the women's outpatient clinic of the Instituto de Medicina Integral Professor Fernando Figueira (IMIP), in Recife, Brazil. The study participants were 277 women who fulfilled the following inclusion criteria: age between 18 and 40 years and presence of bacterial vaginosis diagnosed using Amsel and Nugent criteria concomitantly $(12,13)$. Women were excluded from the study if they presented delayed menstruation or had been diagnosed as pregnant; if they were using or had used any topical or systemic medication, particularly antimicrobial agents over a 30-day period prior to the start of the investigation; if they presented any other vaginal infections (candidiasis or trichomoniasis); if they presented hymen integrity, or if they reported any history suggestive of acute pelvic inflammatory disease.

Patients were considered to be cases of bacterial vaginosis if they presented three or more of Amsel's clinical criteria and, at the same time, a score $\geq 7$ according to Nugent's criteria. The clinical criteria evaluated were: white or grayish genital discharge, $\mathrm{pH}$ higher than 4.5, positive findings from the amine test (whiff test), or presence of clue cells at proportions of $20 \%$ or more on Gram-stained slides. Regarding bacteriological evaluation, patients needed to present a score $\geq 7$ relative to the sum of the bacterial morphological types found in Gram-stained smears from vaginal secretions that were analyzed according to the criteria of Nugent et al. $(1,13,14)$.

The vaginal treatments used were $0.75 \%$ metronidazole gel (artificially colored to make it resemble the pepper tree extract) or pepper tree extract gel. The latter consisted of a mixture of a hydroalcoholic extract of $S$. terebinthifolius Raddi with carbopol gel $(1 \mathrm{~g})$, glycerin $(10 \mathrm{~g})$, sodium benzoate $(0.0175 \mathrm{~g})$, sodium bisulfite $(0.125 \mathrm{~g})$, triethanolamine qsp, pH 4.0-5.0, and distilled water $(2.5 \mathrm{~g})$. Both gels were manufactured by the Hebron Laboratory, and they were similar in appearance, volume, coloring, and $\mathrm{pH}$. They were presented in 60-g tubes that were numbered according to a list of random numbers that had previously been generated by a computer (Epi-Table and Epi-Info 6.04b softwares). The identity of each tube was known only to an assistant who was not a member of the team and who was responsible only for preparing the medications.

The diagnoses were made by means of a gynecological examination performed by a physician who was a participant in the project. After receiving diagnostic confirmation, the patients answered a questionnaire at an interview with a research assistant. These patients were then randomized to one of the two treatment groups. The women were instructed to use the gel in the evenings, at bedtime, for 7 consecutive nights, starting on the day of the interview. Just after randomization, when receiving the medication and becoming aware that the tube could contain either of the two medications to be tested, 2 patients declared that they were allergic to the pepper tree and were then treated with oral metronidazole.

Three swabs were also obtained at the initial consultation in order to culture the vaginal secretion, along with slides of material from the uterine cervix in order to perform the Papanicolaou cytological test. The material was seeded into Thayer Martin medium (gonococci), Sabouraud medium (fungi), Diamond medium (Trichomonas), and blood agar medium (anaerobic agents). Assays to determine the urea, sucrose, maltose, glucose, and lactose concentrations in the 
secretions were also performed. No cultures were performed in media specific for Gardnerella or Mycoplasma.

The first return visit was scheduled to take place between 7 and 14 days later. At this consultation, the women were asked about any occurrences of heat, burning, rash, swelling, reddening, sores, itching, or bleeding, which were considered to be possible adverse effects of the use of the medication. The women had been previously asked to bring along the used applicators in a plastic bag that was provided to them and, on the occasion of this return visit, the applicators were checked to determine whether the women had complied with the prescription.

A second and final return visit was scheduled for a date after the next menstruation. On that occasion, a new gynecological examination was performed by the physician and the tests performed at the initial consultation were repeated. Women who presented no more than one of Amsel's diagnostic criteria and a score of less than seven on Nugent's scale were considered to be cured. The patients who had not achieved a cure received oral metronidazole. On both occasions (first and second return visits), if patients did not come to the scheduled consultation, attempts were made to contact them by telephone, followed by sending letters. If these methods were unsuccessful, these individuals were actively sought in their homes.

The sample size was calculated in such a way that would permit to compare the effectiveness of the two treatments. A clinical cure rate of $85 \%$ was predicted for the group treated with metronidazole gel (15) and a difference of $15 \%$ (cure rate of $70 \%$ ) for the group treated with pepper tree extract gel, with a $95 \%$ confidence interval and a power of $80 \%$. Thus, the sample size required was estimated to be 266 patients (133 in each group).

To compare the frequencies of achieving a cure and the effects that the two treatments had on the vaginal ecosystem, intention-to-treat analysis was performed, with inclusion of all the randomized women using the Epi-Info 3.32 software. Of the total of 277 participants, 136 were treated with vaginal gel containing the pepper tree extract and 139 were treated with metronidazole gel (Figure 1).

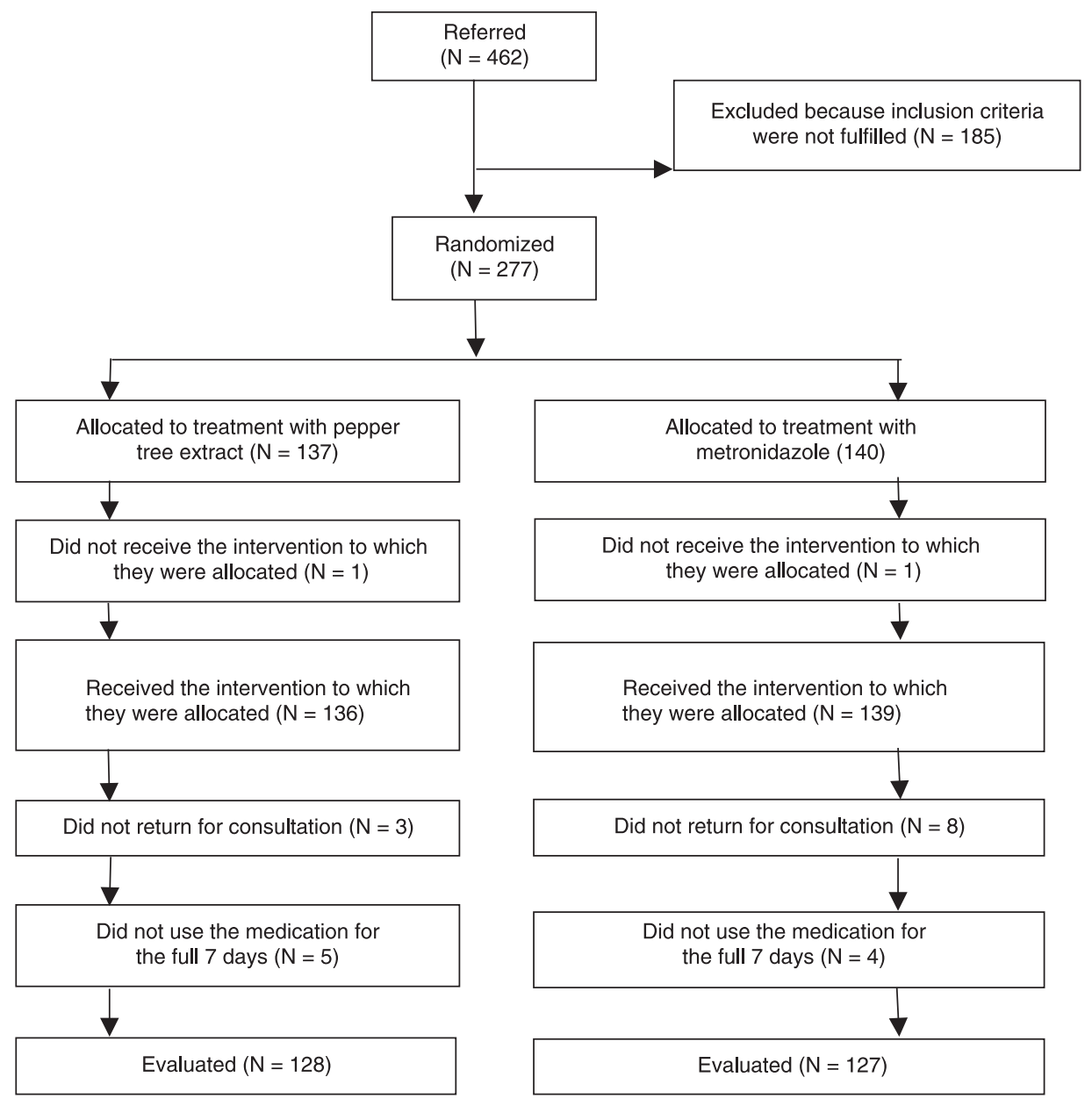

Figure 1. Flow diagram showing patient recruitment and procedures (CONSORT, 2001). 
The final consultation was attended by 255 patients, who thus completed the treatment according to the study protocol. These individuals were compared with regard to the efficacy of the cure between treatments. The chi-square test was used to compare the frequencies of outcomes between the intervention groups and the frequency of the outcome was estimated for each group. Risk ratios and $95 \%$ confidence intervals were calculated for the primary and secondary outcomes.

The present study was conducted in accordance with the postulates of the Declaration of Helsinki and with the recommendations of resolution 196/96 of the National Health Board. The project was approved by the Research Ethics Committee of Instituto de Medicina Integral Prof. Fernando Figueira (IMIP); clinical trial register: \#ISRCTN18987156. The patients who agreed to participate in the study signed an informed consent statement.

\section{Results}

There were no differences between the patients treated with metronidazole and the pepper tree extract in relation to age, marital status, sexual activity during the study period, schooling level, or clinical complaints mentioned, thus indicating that the randomization was effective with regard to distribution of the potential confounding factors between the two groups (Table 1). Concerning the use of contraceptives, since the frequency distribution showed a small difference between treatment groups and, furthermore, the comparison criterion was not just statistical, the risk ratio was adjusted in relation to the contraceptive method. From this calculation it was seen that there was no difference between the crude and adjusted risk ratio values (data not shown).

When evaluating the cure rate using Amsel's criteria separately, it was observed that 29 women $(21.2 \%)$ treated with the pepper tree extract and $87(62.1 \%)$ treated with metronidazole were considered to be cured $(P<0.001)$. The risk of not achieving a cure was 2.15 times greater with the use of the pepper tree extract than with metronidazole. Using Nugent's score alone, 19 women (13.9\%) treated with the pepper tree extract and $79(56.4 \%)$ treated with metronidazole $(P<0.001)$ were considered to be cured, with a relative risk of 1.98 . Finally, using both sets of criteria concomitantly, a so-called total cure was observed for 17 women in the pepper tree extract group, corresponding to $12.4 \%$ of the total, and 79 women $(56.4 \%)$ in the metronidazole group $(P<0.001)$. The relative risk was 2.01 , which means that the risk of not achieving a cure with the pepper tree extract was twice the risk of not achieving it with metronidazole (Table 2).

Table 1. Comparison of the characteristics of patients treated for bacterial vaginosis with a pepper tree extract and with metronidazole for topical vaginal use.

\begin{tabular}{lcc}
\hline Characteristics & Pepper tree extract $(\mathrm{N}=137)$ & Metronidazole $(\mathrm{N}=140)$ \\
\hline Age $($ years $)$ & & \\
Mean \pm SD & $31.4 \pm 5.8$ & $31.4 \pm 5.7$ \\
Median & $33-27(25 \%) 36(75 \%)$ & $32-27(25 \%) 36(75 \%)$ \\
Years of schooling & & \\
$0-4$ & $26(19 \%)$ & $23(16 \%)$ \\
$5-8$ & $27(20 \%)$ & $35(25 \%)$ \\
$>9$ & $84(61 \%)$ & $82(59 \%)$ \\
With a companion & $78(57 \%)$ & $83(59 \%)$ \\
Use of contraceptive methods & $68(45 \%)$ & $84(55 \%)$ \\
Tubal ligation & $28(41.2 \%)$ & $33(39.3 \%)$ \\
Pill & $23(33.8 \%)$ & $27(32.1 \%)$ \\
Intrauterine device & $8(11.8 \%)$ & $13(15.5 \%)$ \\
Injectable & $9(13.2 \%)$ & $9(10.7 \%)$ \\
Others & 0 & $2(2.4 \%)$ \\
Current active sex life & $118(86 \%)$ & $123(88 \%)$ \\
Clinical complaints & $102(74.5 \%)$ & $104(74.3 \%)$ \\
Discharge & $98(71.5 \%)$ & $92(65.7 \%)$ \\
Fish odor & $22(16.1 \%)$ & $29(20.7 \%)$ \\
Dyspareunia & $19(13.9 \%)$ & $27(19.3 \%)$ \\
Heat & &
\end{tabular}

None of the variables were statistically significant. The chi-square test was used to compare the frequencies between the two groups. 
Among the 255 patients who concluded the treatment, 17 women $(12.8 \%)$ treated with the pepper tree extract and 79 women $(60.3 \%)$ treated with metronidazole were considered to be cured according to both sets of criteria (total cure). This corresponded to a relative risk ratio of 2.20 , with a confidence interval of 1.76 to 2.74 and $P<0.001$.

Among the 168 patients who concluded the study protocol but did not attain criteria for a complete cure, 116 were in the group treated with the pepper tree extract and 52 in the metronidazole group. Of these, $66(56.9 \%)$ treated with the pepper tree extract and $35(67.3 \%)$ treated with metronidazole presented partial improvement, corresponding to a decrease in the number of diagnostic parameters present but without reaching a cure (Table 2).

With regard to persistence of the main symptoms, 45 women $(34.1 \%)$ treated with the pepper tree extract and 34 (26\%) treated with metronidazole still presented genital discharge after treatment. Thirty-five patients $(26.5 \%)$ in the pepper tree extract group and $21(16 \%)$ in the metronidazole group continued to present complaints of fish odor (Table 2).

The first return visit, which was scheduled to take place eight days after the first examination and at the end of using the vaginal gel, was attended by 269 women. Among these, only nine women (five in the pepper tree extract group and four in the metronidazole group), i.e., $7 \%$ of the total, had not used the vaginal gel for the full seven days, thereby not complying with the prescribed instructions.
Only three of these women (1\%) had sexual intercourse during the period of medication use, two of whom used condoms during intercourse. Adverse effects occurred in 20 women $(14.8 \%)$ in the pepper tree extract group and in 21 women $(15.7 \%)$ in the metronidazole group. Thus, no statistically significant difference was detected between the groups regarding the presence of adverse effects ( $P$ $=0.84$ ). The most frequent complaint in both groups was colicky abdominal pain (Table 3 ).

Comparison of the effects of the two treatments on the vaginal ecosystem according to the presence of Lactobacillus in colpocytological tests performed at the time of the second return visit indicated that there was a greater presence of these bacilli in the vaginal environment of the women who had used metronidazole gel: 64 positive tests, corresponding to $54 \%$ of the total. On the other hand, among the users of the pepper tree extract, only 13 participants had a positive test ( $11 \%$ of the cases; Table 4$)$.

Analysis of the vaginal ecosystem according to the presence and frequency of the bacteria found in the cultures from vaginal secretions collected after the end of the treatment revealed a greater presence of Lactobacillus among the women who had used the metronidazole vaginal gel, and a greater persistence of Gardnerella and Mobiluncus in the cultures from the users of the pepper tree extract. Both of these differences were statistically significant, with $\mathrm{P}<$ 0.05 (Table 4).

Table 2. Comparison of clinical and bacteriological cures (Amsel and Nugent) among patients treated for bacterial vaginosis with a pepper tree extract and with metronidazole for topical vaginal use.

\begin{tabular}{|c|c|c|c|c|c|}
\hline Cure criteria & $\begin{array}{c}\text { Pepper tree extract }(\mathrm{N}=137) \\
\mathrm{N}(\%)\end{array}$ & $\begin{array}{c}\text { Metronidazole }(\mathrm{N}=140) \\
\mathrm{N}(\%)\end{array}$ & Relative risk & $95 \% \mathrm{Cl}$ & $\mathrm{P}^{\star * *}$ \\
\hline \multicolumn{6}{|l|}{ Amsel } \\
\hline Normal & $29(21.2)$ & $87(62.1)$ & 1.00 & & \\
\hline Abnormal & $108(78.8)$ & $53(37.9)$ & 2.15 & $1.72-2.70$ & $<0.001$ \\
\hline \multicolumn{6}{|l|}{ Nugent } \\
\hline Normal & $19(13.9)$ & $79(56.4)$ & 1.00 & & \\
\hline Abnormal & $118(86.1)$ & $61(43.6)$ & 1.98 & $1.62-2.41$ & $<0.001$ \\
\hline \multicolumn{6}{|l|}{ Total cure } \\
\hline Yes & $17(12.4)$ & $79(56.4)$ & 1.00 & & \\
\hline No & $120(87.6)$ & $61(43.6)$ & 2.01 & $1.65-2.45$ & $<0.001$ \\
\hline \multicolumn{6}{|c|}{ Partial improvement ${ }^{*}$} \\
\hline Yes & $66(56.9)$ & $35(67.3)$ & 1.00 & & \\
\hline No & $50(43.1)$ & $17(32.7)$ & 1.56 & $0.85-2.05$ & 0.27 \\
\hline \multicolumn{6}{|c|}{ Persistence of symptoms ${ }^{* *}$} \\
\hline Discharge & $45(34.1)$ & $34(26.0)$ & 1.31 & $0.90-1.91$ & 0.15 \\
\hline Fish odor & $35(26.5)$ & $21(16.0)$ & 1.65 & $1.02-2.68$ & 0.04 \\
\hline
\end{tabular}

*Among the 168 patients who concluded the study protocol but did not reach the criteria for complete cure. **Main symptoms persisting after treatment. ${ }^{* * *}$ The chi-square test was used to compare the frequencies of outcomes between the groups. 
Table 3. Comparison of the side effects of treatment for bacterial vaginosis with a pepper tree extract and with metronidazole for topical vaginal use.

\begin{tabular}{|c|c|c|c|c|c|}
\hline Side effects & $\begin{array}{c}\text { Pepper tree extract }(\mathrm{N}=135) \\
\mathrm{N}(\%)\end{array}$ & $\begin{array}{c}\text { Metronidazole }(\mathrm{N}=134) \\
\mathrm{N}(\%)\end{array}$ & Relative risk & $95 \% \mathrm{Cl}$ & $\mathrm{P}^{* *}$ \\
\hline Total number of women* & $20(14.8)$ & $21(15.7)$ & 0.95 & $0.54-1.66$ & 0.84 \\
\hline Heat & $5(3.7)$ & $2(1.5)$ & & & \\
\hline Rash & $1(0.7)$ & 0 & & & \\
\hline Itching & $5(3.7)$ & $3(2.2)$ & & & \\
\hline Burning & $4(3.0)$ & 0 & & & \\
\hline Abdominal pain & $11(8.1)$ & $16(11.9)$ & & & \\
\hline
\end{tabular}

*Some patients may have presented more than one symptom. ${ }^{* *}$ The chi-square test was used to compare the frequencies of outcomes between the groups.

Table 4. Effects of treatment for bacterial vaginosis with a pepper tree extract and with metronidazole for topical vaginal use on the vaginal ecosystem.

\begin{tabular}{lccccc}
\hline Parameter & $\begin{array}{c}\text { Pepper tree extract } \\
\mathrm{N}(\%)\end{array}$ & $\begin{array}{c}\text { Metronidazole } \\
\mathrm{N}(\%)\end{array}$ & Relative risk & $95 \% \mathrm{Cl}$ & $\mathrm{P}^{* * *}$ \\
\hline Colpocytology* & 124 & 119 & & & \\
$\quad$ Lactobacillus & $13(11)$ & $64(54)$ & 0.20 & $0.11-0.33$ & $<0.001$ \\
Culture/Gram** & 133 & 128 & & & \\
$\quad$ Gardnerella & $111(84)$ & $51(40)$ & 2.09 & $1.67-2.62$ & $<0.001$ \\
Mobiluncus & $59(44)$ & $18(14)$ & 3.15 & $1.97-5.04$ & $<0.001$ \\
$\quad$ Lactobacillus & $60(45)$ & $83(65)$ & 0.69 & $0.55-0.87$ & $<0.001$ \\
Gram+ cocci & $116(87)$ & $71(56)$ & & & $<0.001$ \\
Gram- cocci & 0 & $1(0.8)$ & & & - \\
Gram+ bacilli & $131(98.5)$ & $127(99.2)$ & & & 0.58 \\
Gram- bacilli & $100(75)$ & $52(41)$ & & & $<0.001$ \\
Fungi & $15(11)$ & $12(0.9)$ & 1.20 & $0.58-2.46$ & 0.61 \\
Gonococci & 0 & $1(0.8)$ & & & \\
Corynebacterium & $124(93)$ & $118(92)$ & & & 0.74 \\
\hline
\end{tabular}

*Data regarding 21 post-treatment colpocytological tests could not be located: nine in the pepper tree extract group and 12 in the metronidazole group. ${ }^{* *}$ Three post-treatment cultures in the metronidazole group were missing. ${ }^{* * *}$ The chi-square test was used to compare the frequencies of outcomes between the groups.

\section{Discussion}

In the present study, the pepper tree extract applied vaginally at the rate of $6 \mathrm{~g}$ a night for 7 days to treat bacterial vaginosis was less effective than the same regimen using metronidazole. There was a low frequency of side effects in both groups, and no statistically significant difference between them in this respect. The most frequent complaint was the appearance of abdominal pain while using the medications, and this was mentioned by women in both treatment groups. Regarding the detection of Lactobacil-
Ius in post-treatment cytological tests, the women who had used metronidazole had a higher frequency of bacilli in their vaginal smears, and this difference was statistically significant. When comparing the effect of the treatments on the vaginal ecosystem, the women who used metronidazole showed better results, with less persistence of anaerobic agents and greater recovery of the microbiota of acidophilic Lactobacillus.

The present study was motivated by the observation that women were embarrassed and inconvenienced by the presence of discharges with a disagreeable odor, with pos- 
sible repercussions on health arising from such discharges $(2,16,17)$. Furthermore, treatment alternatives are being sought, given that the conventional drugs (metronidazole and clindamycin) involve high relapse rates $(18,19)$. Finally, it was reported in a previous study that the pepper tree extract was effective for curing bacterial vaginosis, since it seemed to preserve the vaginal environment through greater conservation of Lactobacillus (7).

The difference in effectiveness observed between the two treatments was greater than expected, taking into account the results of Amorim and Santos (7), which served as the starting point for the present study. In Amorim's study, a cure rate of $84 \%$ was observed among the patients with bacterial vaginosis using pepper tree extract gel, solely by clinical criteria, while in the present study the cure rate was only $21.2 \%$ among the women who used the pepper tree extract gel. Among the reasons that might explain this difference in results between the present and previous studies, the use of a vaginal gel for a smaller number of days in the present study can be highlighted: 10 days in the previous study versus only 7 days in the present study (7). It may be speculated that using the pepper tree extract for longer periods might have had a more favorable result (7). The cure rate with metronidazole $(62.1 \%)$ was within the limits found in other studies $(6,20)$.

In the present study, the cure rates in both groups using only Nugent's criteria were also low, and even lower than the rates observed using Amsel's parameters. Nugent's criteria are considered by many authors to be the gold standard for diagnosing bacterial vaginosis, although these criteria are difficult to interpret and experience is required in doing so. They are also rarely used for diagnoses in clinical practice (21). Some investigators consider that diagnoses of bacterial vaginosis made solely using Nugent's criteria are limited because they include women with different vaginal microbiotas in a single positive group (22).

The so-called total cure, for which the criteria for clinical and bacteriological cure were used together, was reached by $12.4 \%$ of the cases in the group treated with the pepper tree extract gel and by $56.4 \%$ in the metronidazole group. The length of follow-up is probably the most important variable in evaluating the effectiveness of any treatment for bacterial vaginosis (14). Cure measurements made just after concluding the treatment show higher cure rates (80-90\%) than those made 1 month or more after treatment $(60-70 \%)(16,17)$. In the present clinical trial, the cure was

\section{References}

1. O'Brien RF. Bacterial vaginosis: many questions - any answers? Curr Opin Pediatr 2005; 17: 473-479.

2. Nyirjesy $P$. Vulvovaginal candidiasis and bacterial vaginosis. Infect Dis Clin North Am 2008; 22: 637-652, vi.

3. Yudin $\mathrm{MH}$. Bacterial vaginosis in pregnancy: diagnosis, gauged 30 to 45 days after treatment, since the patients returned for the second examination after their menstrual period subsequent to ending the medication. The observed effectiveness of metronidazole $(56.4 \%)$ agreed with the literature, if the time elapsed until assessing the cure is taken into consideration. This should be compared with $12.4 \%$ for pepper tree extract-treated patients.

Another important point is that, because the pathogenesis of vaginosis is unknown, reinfection cannot be precisely differentiated from recurrence. Recurrence rates of 15 to $30 \%$ of the cases, between 30 to 90 days after treatment, have been described. Since the women in the present study returned within this time limit, recurrence may have occurred in some cases that were considered not to be cured (23). Other investigators have demonstrated that the presence of Mobiluncus may cause higher recurrence rates since some lineages of this microorganism present resistance to metronidazole $(8,24)$.

Some of the women were unable to achieve a complete cure, but some of the diagnostic parameters disappeared (particularly among the clinical criteria). Thus, these women were considered to have achieved partial improvement, which clinically often meant that the patients felt that they were "cured". However, it is well known that only a very small percentage of women are able to precisely identify the symptoms of bacterial vaginosis (25). The same is true regarding low rates of persistence of the main symptoms of bacterial vaginosis $(14,25)$.

A survey of the literature only revealed one more study in which extracts from Schinus (Brazilian pepper tree) were used to treat disorders of the vaginal ecosystem, other than the two already cited that were published in 2002 and 2003. This was a randomized single-blind clinical trial that compared several formulations prepared from the pepper tree for vaginal use among women with a variety of complaints. The results of this trial were inconclusive because of the small sample selected (26).

The topical vaginal use of the pepper tree extract was unable to fill the gap that exists with regard to treatments for bacterial vaginosis.

\section{Acknowledgments}

Research partially supported by Hebron Laboratory by supplying the medication used

screening, and management. Clin Perinatol 2005; 32: 617627.

4. Sobel JD. What's new in bacterial vaginosis and trichomoniasis? Infect Dis Clin North Am 2005; 19: 387-406.

5. Cauci S, Hitti J, Noonan C, Agnew K, Quadrifoglio F, Hillier 
SL, et al. Vaginal hydrolytic enzymes, immunoglobulin A against Gardnerella vaginalis toxin, and risk of early preterm birth among women in preterm labor with bacterial vaginosis or intermediate flora. Am J Obstet Gynecol 2002; 187: 877881.

6. Centers for Diseases Control and Prevention (CDC). Sexually transmitted diseases treatment guidelines. Morb Mortal Wkly Rep 2006; 55: 50.

7. Amorim MMR, Santos LC. Tratamento da vaginose bacteriana com gel vaginal de aroeira (Schinus terebinthifolius Raddi): ensaio clínico randomizado. Rev Bras Ginecol Obstet 2003; 2: 95-102.

8. Nyirjesy P, Mclntosh MJ, Steinmetz JI, Schumacher RJ, Joffrion JL. The effects of intravaginal clindamycin and metronidazole therapy on vaginal mobiluncus morphotypes in patients with bacterial vaginosis. Sex Transm Dis 2007; 34: 197-202.

9. Drago L, De Vecchi E, Nicola L, Zucchetti E, Gismondo MR, Vicariotto F. Activity of a Lactobacillus acidophilus-based douche for the treatment of bacterial vaginosis. J Altern Complement Med 2007; 13: 435-438.

10. Simões CM. Plantas da medicina popular do Rio Grande do Sul. Porto Alegre: Editora da Universidade (UFRGS); 1988.

11. Santos LC, Amorim MMR. Uso da aroeira (Schinus terebinthifolius Raddi) para tratamento de infecções vaginais. Femina 2002; 30: 339-342.

12. Amsel R, Totten PA, Spiegel CA, Chen KC, Eschenbach D, Holmes KK. Nonspecific vaginitis. Diagnostic criteria and microbial and epidemiologic associations. Am J Med 1983; 74: $14-22$

13. Nugent RP, Krohn MA, Hillier SL. Reliability of diagnosing bacterial vaginosis is improved by a standardized method of Gram stain interpretation. J Clin Microbiol 1991; 29: 297 301.

14. Simoes JA, Bahamondes LG, Camargo RP, Alves VM, Zaneveld LJ, Waller DP, et al. A pilot clinical trial comparing an acid-buffering formulation (ACIDFORM gel) with metronidazole gel for the treatment of symptomatic bacterial vaginosis. Br J Clin Pharmacol 2006; 61: 211-217.

15. Ferris DG, Litaker MS, Woodward L, Mathis D, Hendrich J. Treatment of bacterial vaginosis: a comparison of oral metronidazole, metronidazole vaginal gel, and clindamycin vaginal cream. J Fam Pract 1995; 41: 443-449.

16. Larsson PG, Forsum U. Bacterial vaginosis - a disturbed bacterial flora and treatment enigma. APMIS 2005; 113: 305-316.

17. Hillier SL, Lipinski C, Briselden AM, Eschenbach DA. Efficacy of intravaginal $0.75 \%$ metronidazole gel for the treatment of bacterial vaginosis. Obstet Gynecol 1993; 81: 963-967.

18. Sobel JD, Ferris D, Schwebke J, Nyirjesy P, Wiesenfeld HC, Peipert J, et al. Suppressive antibacterial therapy with $0.75 \%$ metronidazole vaginal gel to prevent recurrent bacterial vaginosis. Am J Obstet Gynecol 2006; 194: 1283-1289.

19. Wilson J. Managing recurrent bacterial vaginosis. Sex Transm Inf 2004; 80: 8-11.

20. Swidsinski A, Mendling W, Loening-Baucke V, Swidsinski S, Dorffel Y, Scholze J, et al. An adherent Gardnerella vaginalis biofilm persists on the vaginal epithelium after standard therapy with oral metronidazole. Am J Obstet Gynecol 2008; 198: 97.e1-97.e6.

21. Gutman RE, Peipert JF, Weitzen S, Blume J. Evaluation of clinical methods for diagnosing bacterial vaginosis. Obstet Gynecol 2005; 105: 551-556.

22. Pereira L, Culhane J, McCollum K, Agnew K, Nyirjesy P. Variation in microbiologic profiles among pregnant women with bacterial vaginosis. Am J Obstet Gynecol 2005; 193: 746-751.

23. Brotman RM, Erbelding EJ, Jamshidi RM, Klebanoff MA, Zenilman JM, Ghanem KG. Findings associated with recurrence of bacterial vaginosis among adolescents attending sexually transmitted diseases clinics. J Pediatr Adolesc Gynecol 2007; 20: 225-231.

24. Spiegel CA, Amsel R, Holmes KK. Diagnosis of bacterial vaginosis by direct Gram stain of vaginal fluid. J Clin Microbiol 1983; 18: 170-177.

25. Patterson JL, Girerd PH, Karjane NW, Jefferson KK. Effect of biofilm phenotype on resistance of Gardnerella vaginalis to hydrogen peroxide and lactic acid. Am J Obstet Gynecol 2007; 197: 170-177.

26. Costerton W, Veeh R, Shirtliff M, Pasmore M, Post C, Ehrlich $\mathrm{G}$. The application of biofilm science to the study and control of chronic bacterial infections. J Clin Invest 2003; 112: 14661477. 